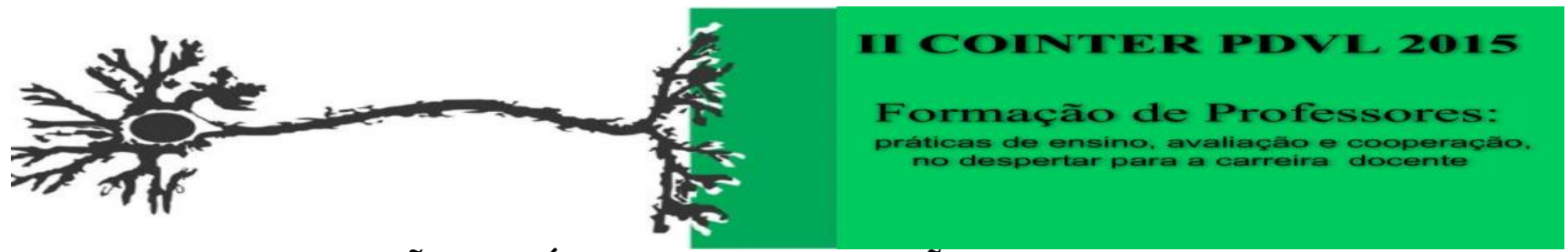

\title{
ENSINO DE LIGAÇÕES QUÍMICAS NA EDUCAÇÃO DE JOVENS E ADULTOS: UMA PROPOSTA CONTEXTUALIZADA ALIADA À EXPERIMENTAÇÃO
}

\author{
Apresentação: Comunicação Oral \\ Flávia Rhuana Pereira Sales ${ }^{1}$; Carlindo Maxshweel Querino da Silva ${ }^{2}$; Niely Silva de Souza ${ }^{3}$ \\ Alessandra Marcone Tavares Alves de Figueirêdo ${ }^{4}$
}

\section{Resumo}

A maioria dos discentes pertencentes a modalidade da Educação de Jovens e Adultos (EJA) apresenta dificuldades no que concerne à disciplina Química que, atreladas à desmotivação e ao constante uso de metodologias estáticas configuram em uma falta de interesse por parte destes alunos, minimizando seu progresso cognitivo. Dentro dessa conjuntura, o uso de recursos metodológicos que valorizam o conhecimento já existente entre seus integrantes, ressaltando sua importância, validando-o por meio dos conceitos científicos, anteriormente conjugados à abstração, enaltece uma aprendizagem significativa. Diante disso, esta intervenção desenvolveu-se com a finalidade de facilitar o processo de ensino-aprendizagem no ensino de Química da EJA, fazendo uso da contextualização, experimentação e aplicação de uma atividade lúdica acerca de Ligações Químicas, com principal enfoque nas Ligações Iônicas. A aplicação fora realizada numa turma do $4^{\circ}$ período do Curso Técnico de Eventos vinculado ao Programa Nacional de Integração da Educação Profissional com a Educação Básica na Modalidade da Educação de Jovens e Adultos (PROEJA), no período noturno do Instituto Federal de Educação, Ciência e Tecnologia da Paraíba (IFPB) câmpus João Pessoa. Dentro desta perspectiva, a experimentação fora utilizada com intuito de favorecer uma aprendizagem substancial, coadunando teoria e prática numa concepção problematizadora, tornando o universo micro da Química em situações macro correlacionadas à aprendizagem sensorial dos discentes. No decorrer deste desenvolvimento, os alunos postaram-se abertos aos diálogos e as situações propostas pelos docentes, compartilhando suas experiências a respeito da temática, aperfeiçoando seus conhecimentos prévios, sem deixá-los de lado, destacandoos como principal caminho para efetivar uma aprendizagem que valorize tais conhecimentos, evidenciando-os para tornar a aprendizagem significativa e priorizando o pleno desenvolvimento do cidadão que se insere na sociedade atual.

Palavras-Chave: ensino de química, educação de jovens e adultos, contextualização, experimentação.

\section{Introdução}

Atualmente as mudanças na sociedade são constantes, assim como no Ensino, alicerce fundamental para a formação da cidadania. Apesar disto, a Educação no país é um dos setores mais precários e sabe-se que é difícil mudar essa realidade, ainda que influencie diretamente nas escolhas das crianças e dos adolescentes, sendo estas, razões cabíveis à evasão escolar. Não obstante, quando

\footnotetext{
${ }^{1}$ Licenciatura em Química, IFPB, flavia.rhuana@outlook.com

${ }^{2}$ Licenciatura em Química, IFPB, maxshweel@gmail.com

${ }^{3}$ Mestranda em Educação e Multiculturalidade, FURNE-Campina Grande, niely.jc@gmail.com

${ }^{4}$ Doutora em Química, IFPB, alessandratavaresfigueiredo@ifpb.edu.br
} 
se volta a atenção para a modalidade da Educação de Jovens e Adultos (EJA) percebe-se uma maior dificuldade, visto que uma das principais características desse público é a precoce inserção necessária do discente no mundo do trabalho.

Diante deste contexto, algumas disciplinas podem despertar nos jovens uma desmotivação da prática escolar, oportunizando ao docente a chance de alterar esse quadro a partir de uma adaptação metodológica, pois a maioria das escolas públicas, lamentavelmente, persiste no exercício do ensino tradicional (quadro e giz). Tal metodologia desfavorece o processo de ensinoaprendizagem, pois o docente assume-se detentor do conhecimento enquanto o discente torna-se apenas um receptor de informações, tendo como obrigação, assimilar o que lhe é transmitido, reproduzindo-as.

A Química é uma das disciplinas na área das Ciências Exatas mais "detestadas" por parte dos discentes, em especial na EJA, principalmente quando é abordada por meio desta metodologia ultrapassada, tornando a Ciência abstrata, designando ao estudante uma ideia de disciplina 'chata' e sem nenhuma correlação com o cotidiano. Diante dessa problemática, este trabalho objetiva utilizar estratégias metodológicas diversificadas, como o uso de Sequências Didáticas (SD), com intuito de favorecer a compreensão dos conteúdos químicos, bem como a ressignificação dos conhecimentos inseridos na vivência do alunado.

\section{Fundamentação Teórica}

A Educação, enquanto direito atrelado às cláusulas pétreas da Constituição Federal de 1988, consiste na garantia deste direito social a todos que compõem a sociedade brasileira. De acordo com a Lei de Diretrizes e Bases da Educação Nacional, LDB - Lei nº 9.394 de 1996, em seu artigo 1ª Educação caracteriza-se como os "processos que se desenvolvem na vida familiar, na convivência humana, no trabalho, nas instituições de ensino e pesquisa, nos movimentos sociais e organizações da sociedade civil e nas manifestações populares” (BRASIL, 1996).

A Educação de Jovens e Adultos, assegurada por meio da LDB, artigo 4 $4^{\text {a }}$, parágrafo VII, garante a oferta desta modalidade na educação pública, fazendo uso de adequadas características às suas necessidades e disponibilidades (BRASIL, 1996). Com o advento desta nova lei, a EJA assumiu três funções distintas dentro de seu campo de atuação, função reparadora, equalizadora e qualificadora, sendo esta última definida, segundo Carneiro (2014) como a capacitação de seu integrante para o exercício da educação permanente, potencializando assim, as chances de inserção na sociedade do conhecimento.

Diferentemente dos alunos pertencentes ao Ensino Regular, os estudantes da EJA possuem, em sua grande maioria, pessoas que não tiveram oportunidade de terminar seus estudos na idade 
sistemática. De acordo com Queiroz, Massena e Santos (2013, p. 3) “o motivo dessa diferença provém de diversos fatores, dentre eles, o fato de os alunos da EJA possuírem traços de vida, origens, idades, vivências profissionais, históricos escolares, ritmos de aprendizagem e estruturas de pensamento, completamente variados". São alunos que "trazem uma visão de mundo mais relacionada ao ver e ao fazer, uma visão de mundo apoiada numa adesão espontânea e imediata às coisas que vê" (BRASIL, 2006, p. 5). São alunos que vivem à margem do sistema de Ensino Brasileiro, que precisam de uma política pública adequada ao seu ritmo, respeitando seus conhecimentos construídos por meio das relações interpessoais e vivências individuais.

Diante desta situação, fora instituído por meio do Decreto $n^{\circ} 5.478$ de 24/06/2005, o Programa de Integração da Educação Profissional ao Ensino Médio na Modalidade Educação de Jovens e Adultos - PROEJA, com intuito de ofertar o Ensino Técnico integrado ao Ensino Médio gratuito, do qual muitas vezes, o público da EJA é excluído (BRASIL, 2009).

No que concerne ao Ensino de Ciências, em particular o Ensino de Química, prima-se o uso de metodologias estáticas e que não valorizam a participação influente do discente no processo de ensino-aprendizagem. O professor transmite conhecimento e o aluno apenas absorve, sem nenhuma criticidade. Nesta perspectiva, de acordo com Duarte et al (2014, p. 376) "a educação deveria superar a condição transmissora do conhecimento para propiciar a autonomia intelectual e política do cidadão", garantindo o pleno desenvolvimento do aluno.

O elo entre o Ensino de Ciências e a EJA dá-se por meio da significação dos conceitos científicos ligados ao cotidiano dos discentes desta modalidade, ou seja, é por meio das situações diárias que a aprendizagem destes conceitos torna-se viável, à medida que os jovens e adultos encontram uma real importância no contato da Ciência. Segundo Santos e Souza,

a aproximação entre o ensino de ciências e a educação de jovens e adultos é feita por meio das discussões que reforçam o caráter da utilidade do conhecimento científico na vida cotidiana do indivíduo, desconsiderando questões relacionadas à visão crítica das relações entre ciência, tecnologia e sociedade e à preocupação com a construção da autonomia dos(as) estudantes (2011, p. 3).

Os alunos partícipes da EJA “chegam à sala de aula, repleto de teorias, explicações e hipóteses" (BRASIL, 2006, p. 7). Cabe ao docente discernir acerca das metodologias adequadas a essa realidade, valorizando este conhecimento, contribuindo para a consolidação da aprendizagem significativa. Em consonância com Tavares (2009, p. 94-95),

quando o aprendiz tem pela frente um novo corpo de informações e consegue fazer conexões entre esse material que lhe é apresentado e o seu conhecimento prévio em assuntos correlatos, ele estará construindo significados pessoais para essa informação, transformando-a em conhecimento, em significados sobre o conteúdo apresentado.

Essas construções pessoais congruentes ao conhecimento científico incorporado no 
cotidiano desenvolvem-se por meio da contextualização. Em consenso à Freire (1997, p. 49), a aprendizagem ocorre "a partir da situação presente, existencial, concreta, refletindo o conjunto de aspirações do povo [...]”. De acordo com os Parâmetros Curriculares Nacionais do Ensino Médio, a contextualização é um recurso metodológico que auxilia a busca de um novo significado ao conhecimento escolar, visto que, a Ciência perpassa as ações diárias da sociedade, desmistificando seu acesso e compreensão.

Dentre os recursos metodológicos acessíveis aos discentes de Química, a experimentação, base epistemológica desta Ciência, fundamenta os conceitos químicos construídos ao decorrer de seu estudo, uma vez que, "a realização de experimentos didáticos pode ser uma tática considerável de elaboração de situações reais nas quais os conhecimentos obtidos em sala de aula se aplicam" (NOVAES, 2013 apud SILVA; SOUZA; SANTOS, 2014, p. 1). Ao entrarem em contato com a prática experimental, característica histórico-cultural da Química, os discentes se sentem motivados e demonstram uma melhoria na sua participação perante as aulas.

A docência Química, inserida no sistema educacional brasileiro, encontra-se degradada diante do contínuo uso de metodologias improgressivas, culminando no esmaecimento do que se propõe ensinar e no que se espera aprender. Além disso, a falta de tempo hábil aliada a esse contexto torna o ensino de Química na EJA insignificante. Nesta conjuntura, o uso de Sequências Didáticas torna-se viável para superação desta problemática, pois discorre em várias atividades sequenciadas, de acordo com uma proposta de progressão de desafios ou de problemas a serem resolvidos pelos alunos (BRASIL, 2006). Ferramentas como a experimentação e a contextualização incorporadas ao uso de atividades sequenciadas "pressupõe conhecimento sobre o conteúdo a ser aprendido e uma visão didática sobre os processos de aprendizagem na área de conhecimento a que ela pertence" (BRASIL, 2006, p. 35).

Além destas estratégias didáticas, a utilização das atividades lúdicas pode colaborar bastante na construção dos conceitos e interação professor-aluno, que se julga necessário para favorecer um âmbito escolar mais dinâmico e participativo. Esta atividade é um recurso didático educativo que pode ser exercido em momentos distintos, como numa ilustração de tópicos fundamentais ao contexto trabalhado, uma simples apresentação de conteúdo, como uma revisão ou síntese de conceitos e avaliação de conteúdos já elaborados (CUNHA, 2004).

A utilização de SD, considerada um recurso didático inovador, objetiva favorecer o processo de ensino-aprendizagem, colocando o estudante em evidência, confrontando sua participação ativa em todas as etapas desse processo. 


\section{Metodologia}

Esta proposta metodológica foi aplicada numa turma do $4^{\circ}$ período de um curso profissionalizante do PROEJA, no período noturno, com 20 alunos participantes do Instituto Federal de Educação, Ciência e Tecnologia da Paraíba (IFPB), câmpus João Pessoa. A proposta foi desenvolvida em 3 (três) aulas de 50 (cinquenta) minutos cada, trabalhada em dois dias, abordando o conteúdo de Ligações Químicas com enfoque em Ligações Iônicas, designado conforme o Plano de Disciplina sugerido pelo professor regente da turma.

Neste estudo, foi empregado uma abordagem qualitativa, que é identificada por meio de uma análise das interações do público, o qual direciona o rumo da pesquisa, mediante o pesquisador. Tal abordagem, "não trabalha com estatísticas e regras rígidas, mas realiza descrições, análises e interpretações de caráter subjetivo" (ALVÂNTARA; VESCE, 2008, p. 2209). E ainda, uma pesquisa participante, que segundo Brandão e Borges (2007, p. 54), o pesquisador deve "partir da realidade concreta da vida cotidiana dos próprios participantes individuais e coletivos do processo", para assim, criar solidariamente valores e conhecimentos.

O desenvolvimento desta práxis se baseou na elaboração de uma Sequência Didática com o uso de ferramentas metodológicas que pudessem oportunizar uma aprendizagem significativa. Desta maneira, o conteúdo de Ligações Químicas foi trabalhado de forma contextual, em que os conhecimentos químicos foram aliados ao conhecimento empírico do alunado. Além disso, instrumentos metodológicos que auxiliassem na edificação dos conceitos, foram utilizados, como: recursos audiovisuais (data show), experimentos, avaliação inicial (AI) e uma atividade lúdica que serviu como avaliação final (AF).

Para a primeira aula, foi preparado uma AI com o intuito de inspecionar o nível de conhecimento dos discentes em relação ao conteúdo que seria abordado, bem como uma apresentação de slides que facilitasse a visualização da estrutura de um átomo, íon (cátion e ânion) e a formação de ligações iônicas, pois o assunto, por ser considerado pela maioria abstrato, gera uma dificuldade e desestimula o alunado. Após uma explanação dos conceitos, o docente exemplificou algumas ligações iônicas presentes no cotidiano dos discentes.

$\mathrm{Na}$ segunda aula, os estudantes foram direcionados para o laboratório de Química, disponibilizado pelo IFPB, para a realização da aula experimental. A bancada foi organizada com três circuitos elétricos básicos e algumas soluções, afim de averiguar a condução de eletricidade, tais como: sal de cozinha (Cloreto de Sódio - $\mathrm{NaCl}$ ), vinagre (Ácido Acético - $\mathrm{CH}_{3} \mathrm{COOH}$ ) e água sanitária (Hipoclorito de Sódio - $\mathrm{NaClO}$ ), todos em meio aquoso e água potável. A turma foi 
dividida em três grupos, posicionados em cada circuito para assim, dar continuidade a atividade.

Para finalizar a aplicação da SD, na terceira aula uma AF foi executada com a concepção do lúdico, na intenção de investigar os conhecimentos adquiridos pelos discentes. Os estudantes foram informados que iriam participar de um "Bingo Químico", em que as bolas sorteadas iriam corresponder ao número atômico dos elementos. A cada rodada, duas bolas seriam sorteadas e um composto seria formado, com isso, os discentes deveriam escrever em sua cartela se este formaria um composto iônico ou não, baseados na aula expositiva e na aula experimental. Ao final da atividade, o grupo com mais acertos receberia uma premiação em forma de guloseima.

\section{Resultados e Discussão}

Ao avaliar as respostas dadas pelos alunos acerca do significado de Ligações Químicas, presentes na AI aplicada na primeira aula, pôde-se notar algumas afirmações interessantes sobre o que de fato é uma ligação química, como "é um produto químico ligado a outro através dos elétrons" e "ligação é quando uma substância reage com outra substância”. Na segunda questão, os alunos foram questionados a exemplificar materiais usuais que fossem compostos por ligações químicas, dentre os mais diversificados exemplos, predominou-se o gás de cozinha, combustíveis fósseis e remédios.

Por fim, na terceira e última questão fora apresentada uma situação problema baseada na veiculação de acidentes domésticos relacionados a choques elétricos enquanto o indivíduo se encontra molhado ou submerso em água, na qual os discentes precisavam sugerir hipóteses para respondê-la. Examinando as respostas, os alunos caracterizaram tal situação decorrente da "não combinação de água e eletricidade", reafirmando que o conhecimento adquirido pelos alunos da EJA se firmou por meio das vivências sociais e pessoais (BRASIL, 2006).

Finalizado o primeiro momento, fora realizada uma retrospectiva de alguns conceitos necessários ao conteúdo de ligações, bem como a inserção deste último por meio de aula expositiva dialogada auxiliada por recurso visual, fazendo uso da contextualização, caracterizando o "interesse despertado nos alunos quando se trata de assuntos diretamente vinculados ao seu cotidiano" (MOREIRA et al, 2013, p. 1074).

Após a aula conceitual de Ligações Químicas, voltada à Ligação Iônica, os discentes foram dirigidos ao laboratório de Química do IFPB onde foi preparada uma atividade experimental. Separados em três grupos, cada grupo obteve à sua disposição um circuito elétrico e quatro béqueres contendo solução de água com sal, água potável, solução de $\mathrm{NaClO}$ e uma solução de $\mathrm{CH}_{3} \mathrm{COOH}$, respectivamente, conforme Figura 1. 
Figura 1 - Montagem da atividade experimental nas bancadas do laboratório. Fonte Própria.

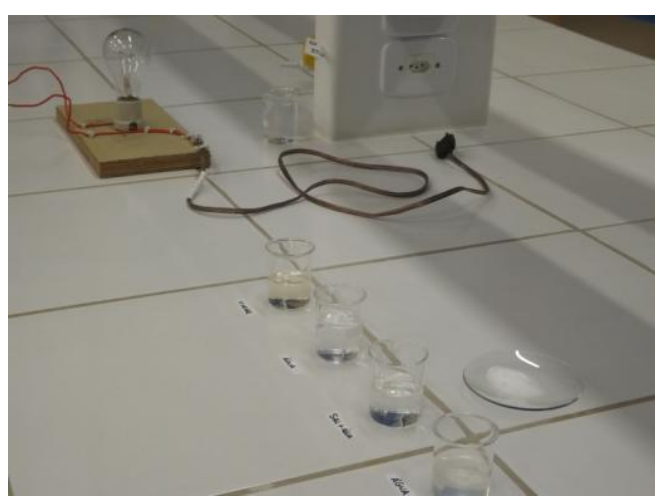

Ao submeterem a solução de vinagre à passagem de corrente, os estudantes verificaram uma luz com intensidade baixa, independentemente de sua concentração. Quando a solução de $\mathrm{NaClO}$ entrou em contato com o circuito, a lâmpada acendeu com intensidade superior à solução de vinagre (Figura 2). O mesmo fenômeno pôde ser observado quando a solução de água com sal fez contato com os fios do circuito.

Figura 2 - Momento em que a corrente elétrica do circuito entrou em contato com a solução de NaClO. Fonte Própria.

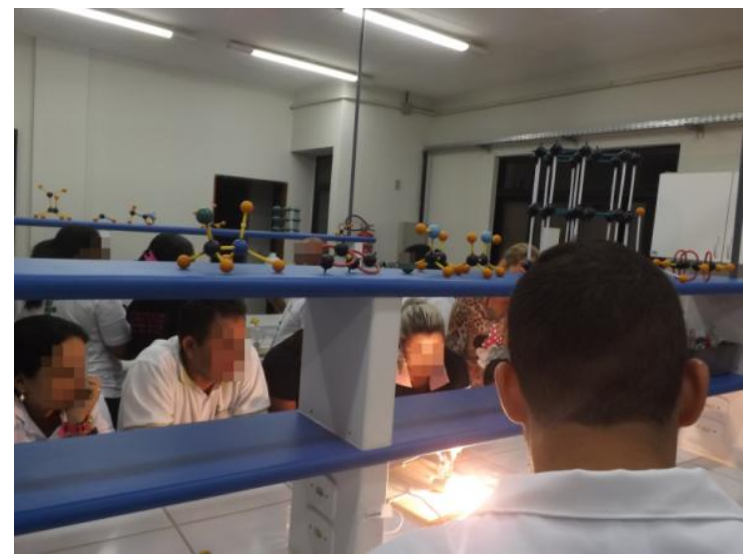

Indagados acerca da experimentação, os alunos começaram a notar os reagentes presentes nas soluções apresentadas. Verificaram que, nas soluções em que a intensidade da luz é maior há presença de metais e ametais, característica da ligação iônica, previamente estudada na forma conceitual.

Entretanto, ao fazerem passar corrente pelo sal de cozinha em estado sólido, pôde-se observar que a lâmpada não acende. Uma aluna questionou "então como é que a água com sal passa corrente?" Outro aluno respondeu "porque a água dissolve o sal”. Foi então explicado que nesse processo ocorre a dissociação iônica, caracterizada pela "separação de cada íon dos íons de carga oposta que rodeiam uma substância em estado sólido" (KOTZ et al, 2009, p. 149). Dando continuidade ao diálogo, os discentes foram questionados sobre o significado de íon e, uma 
estudante concluiu "são elementos que perdem ou ganham elétrons, podem ficar positivo ou negativo”.

Um dos alunos questionou o porquê acontece uma descarga elétrica quando o fio que estava em contato com solo molhado é tocado por um ser humano, relatando experiências de terceiros que trabalham no ramo da Construção Civil. Neste momento, o docente o convidou a fazer a experiência no circuito elétrico utilizando água potável, e o estudante verificou que não há passagem da mesma. Intrigados, os alunos perceberam que apesar de conter algumas substâncias iônicas no seu processo de purificação, a água potável não conduz eletricidade devido à mínima concentração destas substâncias. Questionados sobre o que se passa nos canais de entretenimento em relação ao choque elétrico submerso na água, uma aluna afirmou "há presença de sais de banho ou de cloro nas piscinas e por isso ocorre a passagem da corrente elétrica”.

E para finalizar a aplicação, a terceira e última aula correspondeu a um "Bingo Químico", utilizado como $\mathrm{AF}$, o qual possibilitou a interação aluno-aluno, pois os grupos discutiam e argumentavam entre si, a cada composto sorteado (Figura 3). De acordo com Silva e Navarro (2012, p. 99) "o professor deve proporcionar condições e meios para os alunos se tornarem sujeitos ativos no processo de apropriação do saber sistematizado, para isso deve-se propiciar situações que favoreçam o diálogo entre aluno/aluno".

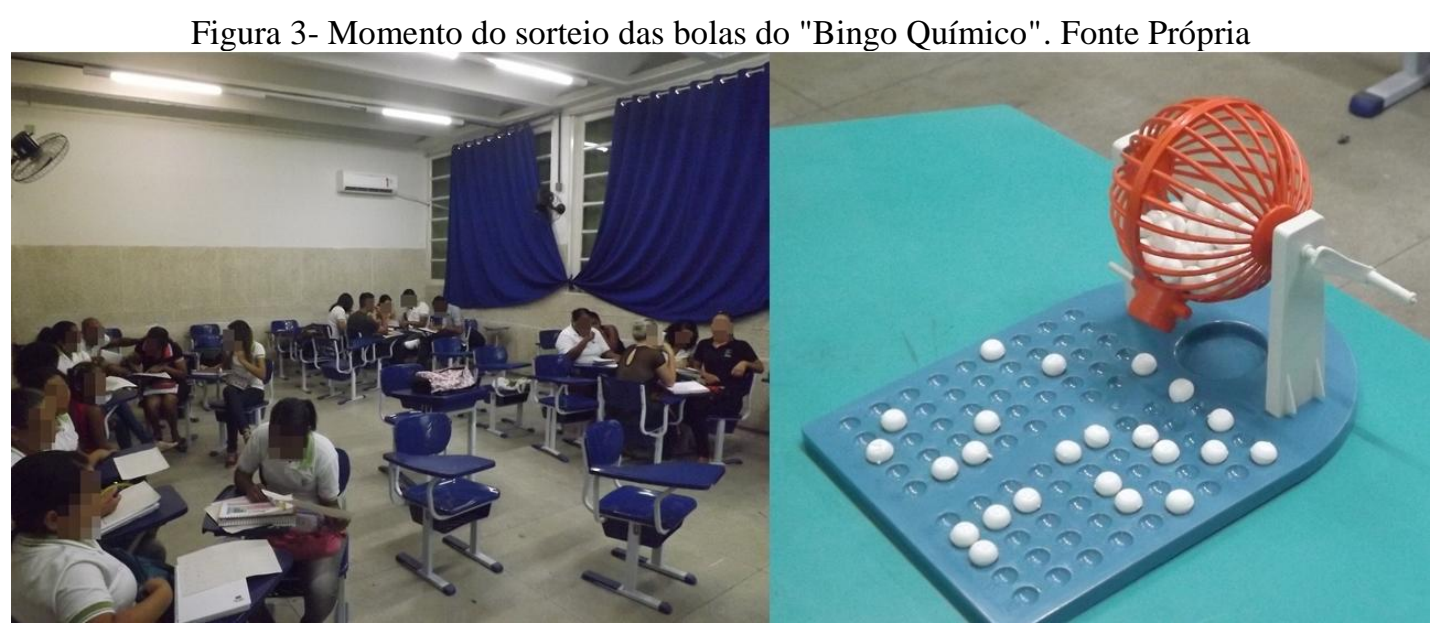

Dentre os doze compostos sorteados, todos os grupos conseguiram acertar acima de $75 \%$ destes, tendo recebido a premiação o grupo que acertou $92 \%$ dos compostos. Diante destes dados, conseguiu-se perceber que o uso deste recurso didático contribuiu na compreensão do conceito de Ligação Iônica, juntamente com a contextualização do conteúdo.

Os discentes mostraram-se motivados diante das atividades propostas, fortalecendo o processo de ensino-aprendizagem, buscando significância às informações adquiridas em suas vivências sociais por meio da difusão da ciência e do cotidiano. As atividades desenvolvidas corroboraram para este processo e a participação dialógica dos alunos apresentou-se como 
ferramenta ao desenvolvimento de um cidadão ativo, participante do meio, modelando à sua percepção.

\section{Conclusões}

Uma nova concepção do ensino de Química apresentada para a turma do Ensino Médio da modalidade de Educação de Jovens e Adultos foi evidenciada nos momentos que houveram interações entre professor-aluno, nos quais foram compartilhados vivências e fatos que puderam ser relacionados com os conceitos abordados em sala de aula, uma vez que os mesmos foram contextualizados, despertando o interesse do alunado.

É de grande relevância destacar o papel do docente como o mediador no processo de ensinoaprendizagem, sendo de sua incumbência investigar e adaptar as possíveis ferramentas metodológicas que possam contribuir para o aperfeiçoamento cognitivo dos discentes, tornando-os pensantes críticos na construção do conhecimento.

Diante do exposto, os recursos didáticos e as estratégias trabalhadas nesse estudo, influenciaram na compreensão dos conceitos, gerando dúvidas, na relação docente-discente, tornando o aluno ativo no âmbito escolar. Portanto, a Química abordada numa perspectiva contextualizada, junto a experimentação de modo significativo, incentivou a curiosidade dos discentes e possibilitou uma aprendizagem significativa.

\section{Referências}

ALVÂNTARA, A. M.; VESCE, G. E. P. "As representações sociais no discurso do sujeito coletivo no âmbito da pesquisa qualitativa." Anais do $8^{\circ}$ Congresso Nacional de Educação. 2008.

BRANDÃO, C. R.; BORGES, M. C. "A pesquisa participante: um momento da educação popular." Revista de Educação Popular 6.1, 2007.

BRASIL, Lei de Diretrizes e Bases da Educação Nacional, Lei № 9.394, de 20 dezembro de 1996.

Ministério da Educação e Cultura. Série: Trabalhando com a Educação de Jovens e Adultos. Brasília: Imprensa Nacional, 2006.

Programa Nacional de Integração Da Educação Profissional Com a Educação Básica na Modalidade De Educação de Jovens e Adultos. Educação Profissional Técnica de Nível Médio, Ensino Médio: Documento Base. Brasília: MEC: 2009.

. Ministério da Educação, Secretaria de Educação Média e Tecnológica. Parâmetros

Curriculares Nacionais: ensino médio. Brasília: Ministério da Educação, 1999. 
CARNEIRO, M. A. LDB fácil: leitura crítico-compreensiva, artigo a artigo. 22a edição Petrópolis, RJ: Vozes, 2014.

CUNHA, M. B. Jogos de Química: Desenvolvendo habilidades e socializando o grupo. ENEQ, 2004.

DUARTE, C. T.; ALMEIDA, F. C. S.; ARRUDA, R. M.; CAMPOS, M. G.; MACHADO, N. G. Ensino de Ciências na EJA: Relato de uma Experiência Didática. In: UNOPAR Científico, Ciências, Humanidades e Educação, Londrina - PR. Volume 15, páginas 375-380. Dezembro/2014.

FREIRE, P. Pedagogia do oprimido. 24 ed. Rio de Janeiro: Paz e Terra, 1997.

KOTZ, J. C.; TREICHEL, P. M.; WEAVER, G. C. Química Geral e Reações Químicas. 1ª ed. São Paulo - SP: Vol 1. Cengage Learning, 2009.

MOREIRA, F. B. F, et al. Ensino de Química na Modalidade EJA: Uma Proposta de Produção de um Material Didático. In: IX Congresso de Iniciação Científica do IFRN, 2013, Currais Novos RN. Anais do IX CONSIG, 2013.

SANTOS, M. N.; SOUZA, M. L. O Ensino de Ciência em turmas da Educação de Jovens e Adultos. In: VII Encontro Nacional de Pesquisa em Educação em Ciências, 2011, Campinas - SP. Anais do VII ENPEC, 2011.

SILVA, C, M.; SOUZA, J.; SANTOS, M. B. H. Contribuições da Experimentação no Processo de Aprendizagem de Cinética Química. In: V Encontro Nacional de Licenciatura, 2014, Natal - RN. Anais do V ENALIC, 2014.

SILVA, O. G.; NAVARRO, E.C. A Relação Professor-Aluno no Processo Ensino-Aprendizagem. Interdisciplinar: Revista Eletrônica da Univar, v. 3, n. 8, p. 95-100, 2012.

QUEIROZ, I. R. L.; MASSENA, E. P.; SANTOS, I.M. O currículo de Química na Educação de Jovens e Adultos em escolas de Ilhéus e Itabuna: o que está sendo ensinado? In: IX Encontro Nacional de Pesquisa em Educação em Ciências, 2013, Águas de Lindóia - SP. Anais do IX ENPEC, 2013.

TAVARES, R. Aprendizagem significativa e o ensino de ciências. In: Ciências \& Cognição, Rio de Janeiro - RJ. Volume 13, páginas 94-100. Março de 2008. 